\title{
Synthesis of nanocrystalline materials through reverse micelles: A versatile methodology for synthesis of complex metal oxides
}

\author{
ASHOK K GANGULI*, SONALIKA VAIDYA and TOKEER AHMAD \\ Department of Chemistry, Indian Institute of Technology, New Delhi 110 016, India
}

\begin{abstract}
We have been successful in obtaining monophasic nanosized oxides with varying chemical compositions using the reverse micellar method. Here we describe our methodology to obtain important metal oxides like ceria, zirconia and zinc oxide. The oxalate of cerium, zirconium and zinc were synthesized using the reverse micellar route. While nanorods of zinc oxalate with dimension, $120 \mathrm{~nm}$ in diameter and $600 \mathrm{~nm}$ in length, could be obtained, whereas spherical particles of size, 4-6 nm, were obtained for cerium oxalate. These precursors were heated to form their respective oxides. Mixture of nanorods and nanoparticles of cerium oxide was obtained. $\mathrm{ZrO}_{2}$ nanoparticles of 3-4 $\mathrm{nm}$ size were obtained by the thermal decomposition of zirconium oxalate precursor. $\mathrm{ZnO}$ nanoparticles $(55 \mathrm{~nm})$ were obtained by the decomposition of zinc oxalate nanorods. Photoluminescence (PL) studies at $20 \mathrm{~K}$ shows the presence of three peaks corresponding to free excitonic emission, free to bound and donor-acceptor transitions. We also synthesized nanoparticles corresponding to $\mathrm{Ba}_{1-x} \mathrm{~Pb}_{x} \mathrm{ZrO}_{3}$ using the reverse micellar route. The dielectric constant and loss were stable with frequency and temperature for the solid solution.
\end{abstract}

Keywords. Reverse micelles; nanorods; photoluminescence; dielectric properties.

\section{Introduction}

Nanomaterials have fascinated the scientific community in the recent past. These materials exhibit unusual properties compared to their bulk counterparts. The physical laws applicable to the materials change as the size of the particles decreases to the nanoregime. Surface and quantum effects result in the modification of the properties, (optical, magnetic and dielectric) of nano-sized particles (figure 1). The dielectric and magnetic properties of oxides depend considerably on the size and shape of the particles. For example, in materials having dipoles show disorder in the dipole and magnetic moments with decrease in size (figure 2). This disorder leads to changes in the dielectric and magnetic properties. A very important property of nanostructured materials is that they can be dispersed in different types of matrix media to impart useful characteristics to the composite. These have immense consequences in flexible polymer composite films with functional properties due to the nano-metals or ceramic additives.

Various methods have been formulated to synthesize nano materials. These include physical methods such as chemical vapour deposition (Roth and Williams 1981; Maruyama and Shionoya 1992), plasma synthesis (Lin et al 2000), spray pyrolysis (De Merchant and Cocivera 1995). Chemical methods include solvothermal (Komarneni et al 1998), oxidant precipitation (Sartale and Lokhande 2000), electrodeposition (Erb 1995), sol-gel synthesis (Chatter-

*Author for correspondence (ashok@chemistry.iitd.ernet.in) jee et al 1993) etc. Such bottom-up approaches followed for the synthesis of nanomaterials should restrict the growth of the nuclei, prevent the agglomeration of particles and maintain the size distribution of these materials. A versatile chemical method to synthesize nanoparticles is the reverse micellar route (Pileni et al 1992; Ahmad et al 2005a; Ahmad and Ganguli 2006). The synthesis via this method does not require specialized or expensive equipments as is required by several physical methods. The reaction takes place in the aqueous cores of the reverse micelles which are dispersed in an organic solvent and are stabilized by a surfactant. The product obtained after the reaction is homogeneous. The morphology of the product can also be controlled as the surfactant aggregates form a variety of structures which are used as templates. The size of the core of the reverse micelles can also be controlled by changing Wo $\left(\left[\mathrm{H}_{2} \mathrm{O}\right] /[\right.$ surfactant $\left.]\right)$. Thus one can alter the morphology as well as the grain size of the product. We have synthesized a variety of materials using this method. These include dielectric oxide nanoparticles (Ahmad et al 2005a; Ahmad and Ganguli 2006) and several metal oxalates such as nanorods of copper and nickel oxalates (Ahmad et al 2005b). In this paper we discuss the synthesis and characterization of ceria, zirconia, zinc oxide and $(\mathrm{Ba}, \mathrm{Pb}) \mathrm{ZrO}_{3}$ by the above method.

\section{Experimental}

The experimental section is divided into the synthesis of (a) cerium oxalate and its decomposition to form cerium 
oxide nanoparticles, (b) zirconia from zirconium oxalate, (c) zinc oxalate nanorods and its decomposition to zinc oxide, and $(\mathrm{d})(\mathrm{Ba}, \mathrm{Pb}) \mathrm{ZrO}_{3}$.

For synthesis of cerium oxalate, zirconium oxalate and zinc oxalate, two different microemulsions with CTAB (surfactant) (spectrochem), 1-butanol (co-surfactant) (qualigens), and isooctane (organic solvent) (spectrochem) and aqueous solution were prepared. One microemulsion contained $0 \cdot 1 \mathrm{M} \mathrm{Ce}\left(\mathrm{NO}_{3}\right)_{3} \cdot 6 \mathrm{H}_{2} \mathrm{O}$ solution, $0 \cdot 1 \mathrm{M}$ zirconyl oxychloride and $0.1 \mathrm{M}$ zinc nitrate solution for cerium oxalate, zirconium oxalate and zinc oxalate, respectively. The other contained $0 \cdot 1 \mathrm{M}$ solution of ammonium oxalate. The two microemulsions were mixed and allowed to stir for $15 \mathrm{~h}$. The precipitates were centrifuged and washed with $1: 1$ mixture of chloroform and methanol and dried at room temperature. The cerium oxalate and zirconium oxalate precursors were decomposed at $500^{\circ} \mathrm{C}$ for $6 \mathrm{~h}$ to obtain cerium oxide and zirconium oxide nanoparticles. Zinc oxalate was decomposed at $450^{\circ} \mathrm{C}(6 \mathrm{~h})$ to obtain $\mathrm{ZnO}$.

The synthesis of the entire solid solution of $\mathrm{Ba}_{1-\mathrm{x}}$ $\mathrm{Pb}_{x} \mathrm{ZrO}_{3}$ was carried out using microemulsions with Tergitol (surfactant) (Aldrich), 1-octanol (co-surfactant) (spectrochem), cyclohexane (organic solvent) (Ranbaxy) m

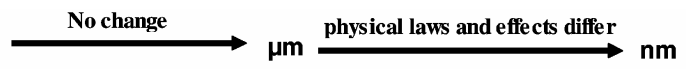

Physical properties

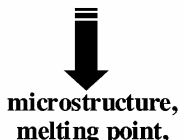

melting point,

hardness

ductile ceramics
Chemical

properties

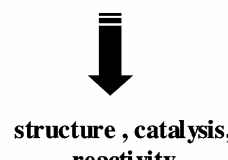

Macroscopic Quantum tunnelling

Figure 1. Flowchart showing changes in various properties in nanodimension.

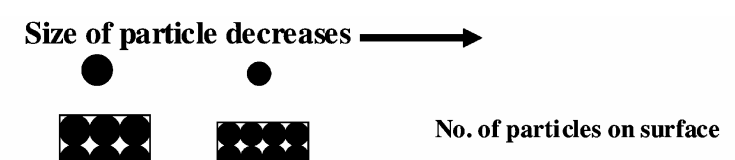

Surface Properties dominate

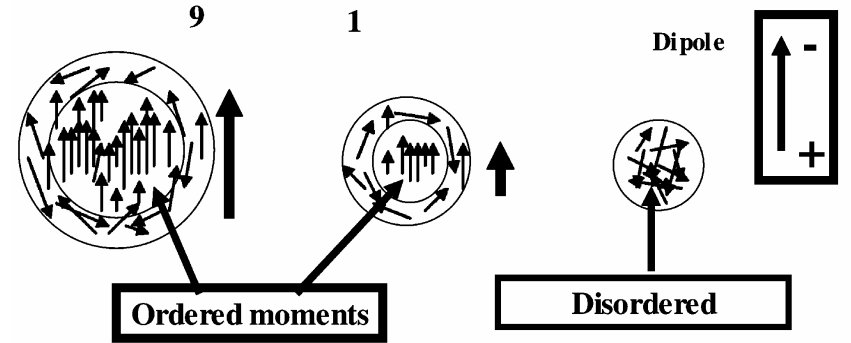

Figure 2. Schematic diagram showing the increase in disorder of dipoles with decrease in the size of particles. and aqueous solution. For $(\mathrm{Ba}, \mathrm{Pb}) \mathrm{ZrO}_{3}$, four different microemulsions were prepared containing $0 \cdot 1 \mathrm{M}$ solution of barium acetate (Aldrich), lead acetate (BDH), zirconyl oxychloride $(\mathrm{CDH})$ and sodium hydroxide $(\mathrm{BDH}, 97 \%)$, respectively. The microemulsions were mixed and stirred overnight at room temperature. A transparent solution was obtained. On evaporating the solvent from the solution at $60 \pm 5^{\circ} \mathrm{C}$, a brown precipitate was obtained which was washed with acetone, centrifuged and then dried in an oven at $60^{\circ} \mathrm{C}$ for $1 \mathrm{~h}$. The product obtained was further heated in air at $500^{\circ} \mathrm{C}$ for $20 \mathrm{~h}$ and subsequently at $800^{\circ} \mathrm{C}$ for $20 \mathrm{~h}$ to get the pure product.

Powder X-ray diffraction studies (PXRD) were carried out on a Bruker D8 advance diffractometer using Ni-filtered $\mathrm{Cu}-\mathrm{K} \alpha$ radiation. Normal scans were recorded with a step size of $0.02^{\circ}$ and step time of $1 \mathrm{~s}$. Raw data was subjected to background corrections and $\mathrm{K} \alpha_{2}$-lines were stripped off. The grain size was calculated using the Scherrer's formula

$$
t=0 \cdot 9 \lambda / B \cos \theta
$$

where $t$ is the diameter of the grain, $\lambda$ the wavelength of radiation ( $\lambda$ for $\mathrm{CuK} \alpha$ is $1.5418 \AA$ ) and $B$ the line broadening which is measured from the full width at half maximum (FWHM) and calculated by the Warren's formula

$$
B^{2}=\left(B_{\mathrm{M}}^{2}-B_{\mathrm{S}}^{2}\right)
$$

where $B_{\mathrm{M}}$ is the full width at half maxima of the sample and $B_{\mathrm{S}}$ the full width at half maximum of the standard quartz with a grain size of around $2 \mu \mathrm{m}$. The cell parameters were determined using a least square fitting procedure on all reflections using quartz as the external standard. TGA/ DTA experiments were carried out on Perkin Elmer Pyris Diamond TGA/DTA system on well ground samples in flowing nitrogen atmosphere with a heating rate of $10^{\circ} \mathrm{C} / \mathrm{min}$. TEM and HRTEM studies were carried out on JEOL JEM 3010 electron microscope operated at $300 \mathrm{kV}$.

Dielectric measurements were carried out on disks of (a) $\mathrm{CeO}_{2}$ nanoparticles sintered at $1000^{\circ} \mathrm{C}$, (b) $\mathrm{ZrO}_{2}$ nanoparticles (synthesized from zirconium oxalate) sintered at $1000^{\circ} \mathrm{C}$ and $(\mathrm{c})(\mathrm{Ba}, \mathrm{Pb}) \mathrm{ZrO}_{3}$ sintered at $1000^{\circ} \mathrm{C}$. The measurements were carried out using Hewlett Packard 4284L multifrequency LCR meter in the range $50 \mathrm{~Hz}-$ $500 \mathrm{kHz}$. Temperature variation studies of the dielectric constant and dielectric loss were carried out in the range $30-300^{\circ} \mathrm{C}$.

For photoluminescence (PL) studies the samples were housed in an optical cryostat with front surface excitation and emitted radiation was collected. The samples were kept in a closed-cycle He refrigerator and excited with $325 \mathrm{~nm}$ line of a He-Cd laser. The PL signal was collected into a $0.46 \mathrm{~m}$ Jobin-Yvon grating monochromator in the wavelength region of 340-900 nm and detected with a UV-enhanced Si detector. The PL data were processed 
using lock-in technique. The spectral response of the system was calibrated using a blackbody source.

\section{Results and discussion}

Cerium oxalate precursor was indexed on the basis of a monoclinic cell with refined lattice parameters of $a=$ 11.311(3) $\AA, b=9.653(3) \AA, c=10.390(3) \AA$ and $\beta=114.5^{\circ}$. The particles were found to be $4-6 \mathrm{~nm}$ as observed from the HRTEM (figure 3a). Note that we have obtained nanoparticles and not nanorods (as earlier obtained for other transition metal oxalates) (Ahmad et al 2004, 2005b). This could be explained due to the trivalent
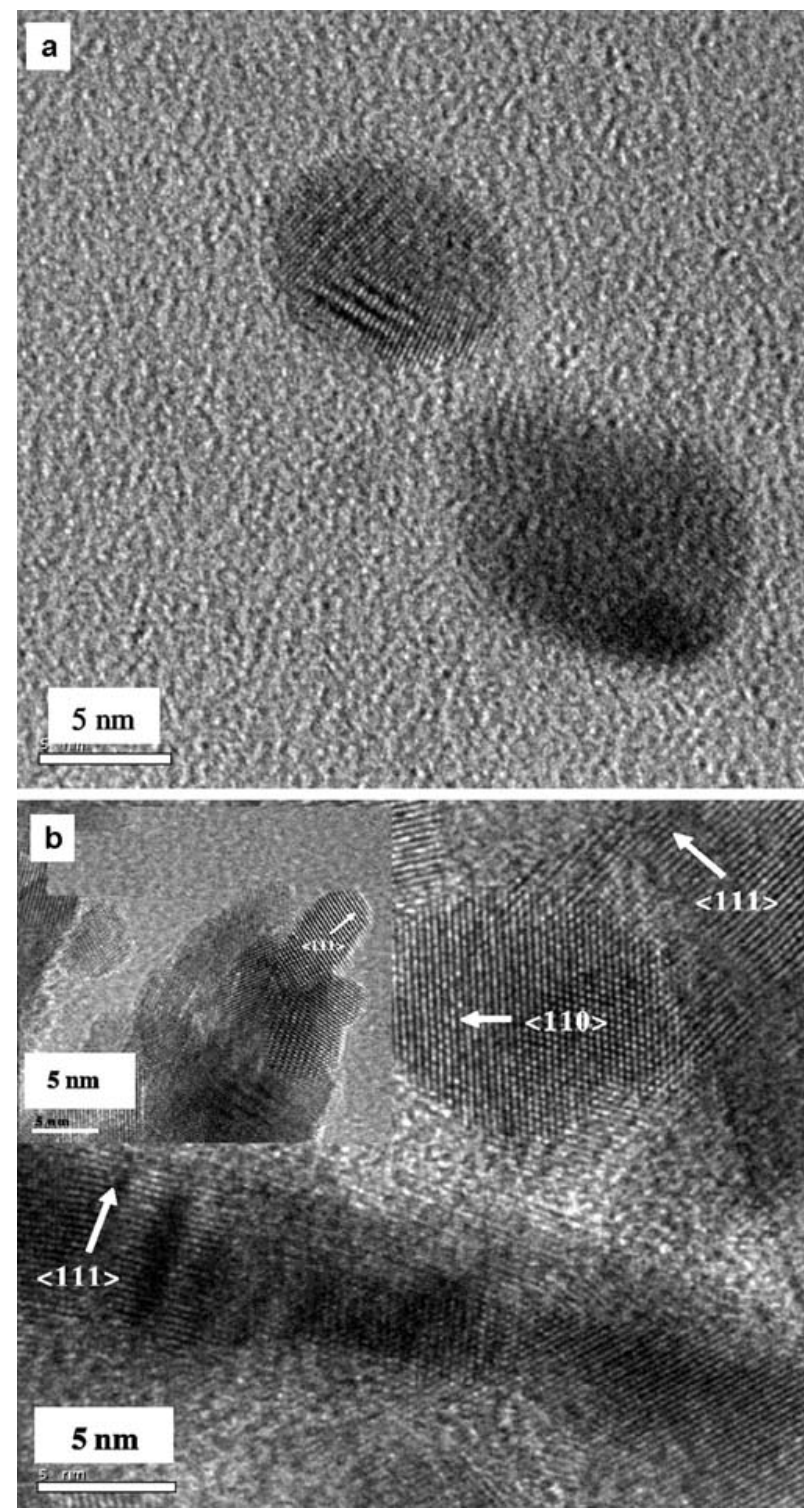

Figure 3. HRTEM images of (a) cerium oxalate and (b) cerium oxide nanoparticles. Inset shows HRTEM images of cerium oxide (obtained from cerium oxalate) showing the growth of nanorods. state of cerium in cerium oxalate whereas in earlier studies (Ahmad et al 2004, 2005b) as in transition metal oxalates, the transition metals were always in the divalent state. The divalent state of the metal ion is appropriate for linear geometry due to the $1: 1$ ratio of $\mathrm{M}^{2+}: \mathrm{C}_{2} \mathrm{O}_{4}^{2-}$ (oxalate ion) and has resulted in the formation of rod like morphology whereas it appears that the trivalent state in case of Ce may be responsible for not allowing the formation of rod-like structure. The cerium oxalate precursor was heated at $500^{\circ} \mathrm{C}$ for $6 \mathrm{~h}$ to form cerium oxide. XRD shows monophasic ceria with lattice parameters close to values reported earlier (JCPDS No. 81-0792). Mixture of nanoparticles and nanorods of $\mathrm{CeO}_{2}$ were observed (Vaidya et al 2007) from the HRTEM studies (figure $3 \mathrm{~b}$ ). The nanoparticles of $\mathrm{CeO}_{2}$ are $10 \mathrm{~nm}$ in size; however, the dimensions of the nanorods are $7 \mathrm{~nm}$ in width and around $30 \mathrm{~nm}$ in length as seen from the HRTEM

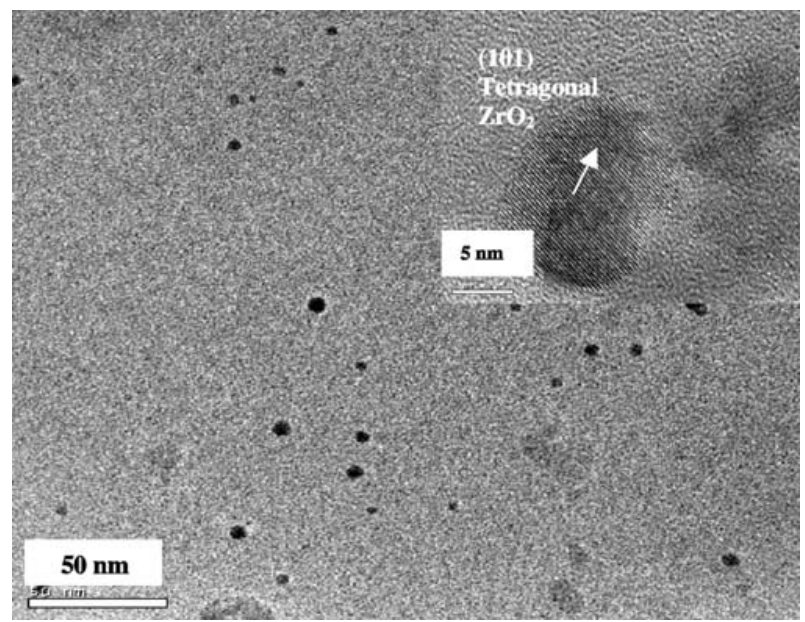

Figure 4. TEM images of nanocrystalline $\mathrm{ZrO}_{2}$. Inset shows HRTEM images for $\mathrm{ZrO}_{2}$

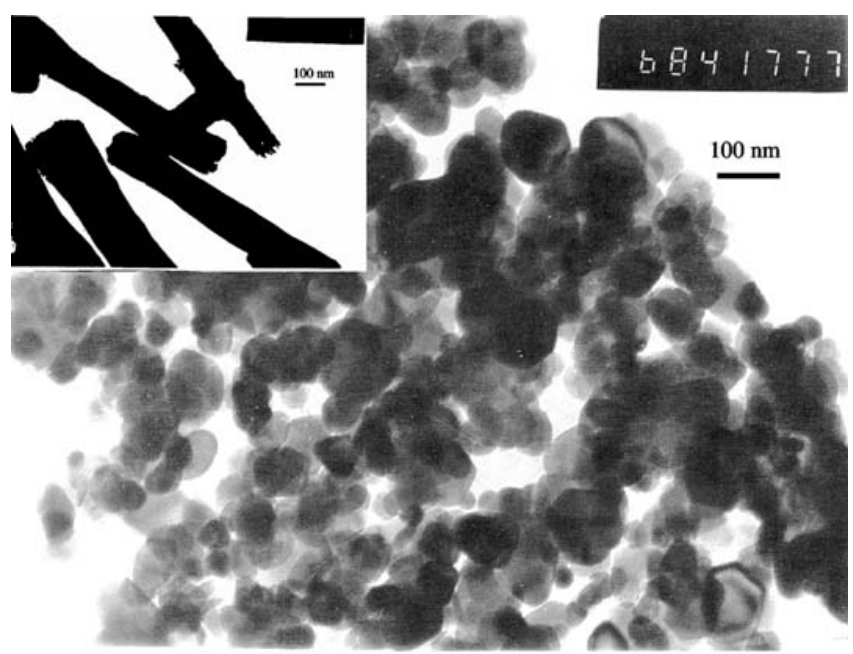

Figure 5. TEM micrograph of zinc oxide nanoparticles. The inset shows TEM micrograph of the nanorods of zinc oxalate 
Table 1. Average particle size and dielectric parameters of $(\mathrm{Ba}, \mathrm{Pb}) \mathrm{ZrO}_{3}$ powders obtained from TEM studies.

\begin{tabular}{lccccc}
\hline $\mathrm{Ba}_{1-x} \mathrm{~Pb}_{x} \mathrm{ZrO}_{3}$ & Particle size $(\mathrm{nm})$ & $\varepsilon(100 \mathrm{kHz})$ & $D(100 \mathrm{kHz})$ & $\mathrm{d} \varepsilon / \mathrm{d} F\left(\mathrm{~Hz}^{-1}\right)$ & $\mathrm{d} \varepsilon / \mathrm{d} T\left({ }^{\circ} \mathrm{C}^{-1}\right)$ \\
\hline$x=0$ & $25( \pm 5)$ & 18.5 & $0 \cdot 3$ & $2 \cdot 01 \times 10^{-5}$ & 0.0033 \\
$x=0.25$ & $22( \pm 3)$ & 76 & $0 \cdot 01$ & $8 \cdot 00 \times 10^{-6}$ & 0.0738 \\
$x=0.50$ & $40( \pm 5)$ & 93.3 & $0 \cdot 09$ & $1.48 \times 10^{-5}$ & $0 \cdot 1040$ \\
$x=0.75$ & $50( \pm 4)$ & 69 & $0 \cdot 09$ & $1.13 \times 10^{-5}$ & 0.0046 \\
$x=1$ & $65( \pm 5)$ & 30.5 & 0.02 & $3.2 \times 10^{-6}$ & 0.0115 \\
\hline
\end{tabular}

image (figure $3 b$ ). It seems that the particles aggregate to form rods as observed in the inset of figure $3 \mathrm{~b}$.

The zirconium oxalate precursor was found to be amorphous. Heating the precursor at $500^{\circ} \mathrm{C}$ for $6 \mathrm{~h}$ led to tetragonal zirconia with $10 \%$ impurity of monoclinic zirconia (Vaidya et al 2007). The refined cell parameters were found to be $a=3 \cdot 957(9) \AA$ and $c=5 \cdot 16(3) \AA$. Note that the tetragonal zirconia is in high temperature phase which has been stabilized at low temperature $\left(500^{\circ} \mathrm{C}\right)$. The particle size was found to be around $3-5 \mathrm{~nm}$ (figure 4). HRTEM image shows lattice fringes corresponding to (101) plane of tetragonal $\mathrm{ZrO}_{2}$ (inset of figure 4).

The powder X-ray diffraction pattern of zinc oxalate precursor obtained by the reverse micellar route was indexed on the basis of a monoclinic cell (Ahmad et al 2006). The average dimensions of the nanorods were $120 \mathrm{~nm}$ in diameter and $600 \mathrm{~nm}$ in length as observed from the TEM image (inset of figure 5). Zinc oxide nanoparticles, obtained by the thermal decomposition of nanorods of zinc oxalate were indexed on the basis of hexagonal cell with the refined lattice parameters of $a=3 \cdot 2498(4) \AA$ and $c=5 \cdot 209(1) \AA$. Figure 5 shows the average size of $\mathrm{ZnO}$ nanoparticles to be $60 \mathrm{~nm}$.

For the oxides corresponding to $\mathrm{Ba}_{1-x} \mathrm{~Pb}_{x} \mathrm{ZrO}_{3}$, the $\mathrm{X}$ ray pattern of $x=0\left(\mathrm{BaZrO}_{3}\right)$ and $x=0.25$ composition was indexed on the basis of a cubic cell. The orthorhombic phase was observed as the value of $x$ in $\mathrm{Ba}_{1-x} \mathrm{~Pb}_{x} \mathrm{ZrO}_{3}$ increases beyond $x=0.25(0.50 \leq x \leq 1)$. The lattice parameters decrease slightly with increase in the value of $x$ ( $\mathrm{Pb}$ content). This is expected due to the smaller ionic radius of $\mathrm{Pb}(\mathrm{II})$ compared to $\mathrm{Ba}(\mathrm{II})\left(r_{\mathrm{Pb}}^{2+}=1.19 \AA, r_{\mathrm{Ba}}^{2+}=\right.$ $1.35 \AA)$. The particle size for different members of the solid solution (heated at $800^{\circ} \mathrm{C}$ ) is given in table 1 . The products sintered at $1000^{\circ} \mathrm{C}$ show slightly higher grain size (55 and $90 \mathrm{~nm}$ for $x=0$ and 1 , respectively).

Dielectric properties of $\mathrm{CeO}_{2}$ nanoparticles synthesized from the oxalate precursor were studied after sintering the compacted disks at $1000^{\circ} \mathrm{C}$. The dielectric constant and loss were found to be stable with frequency. The dielectric constant ( 15 at $500 \mathrm{kHz}$ at room temperature) was nearly stable with temperature, while the dielectric loss shows a constant value $(\sim 0.08$ at $500 \mathrm{kHz}$ at room temperature) till $200^{\circ} \mathrm{C}$ beyond which it rises sharply. The dielectric constant for bulk $\mathrm{CeO}_{2}$ was earlier reported (Logothetidis et al 2004) to be 26. However, there was no mention of the grain size and the sintering temperature.

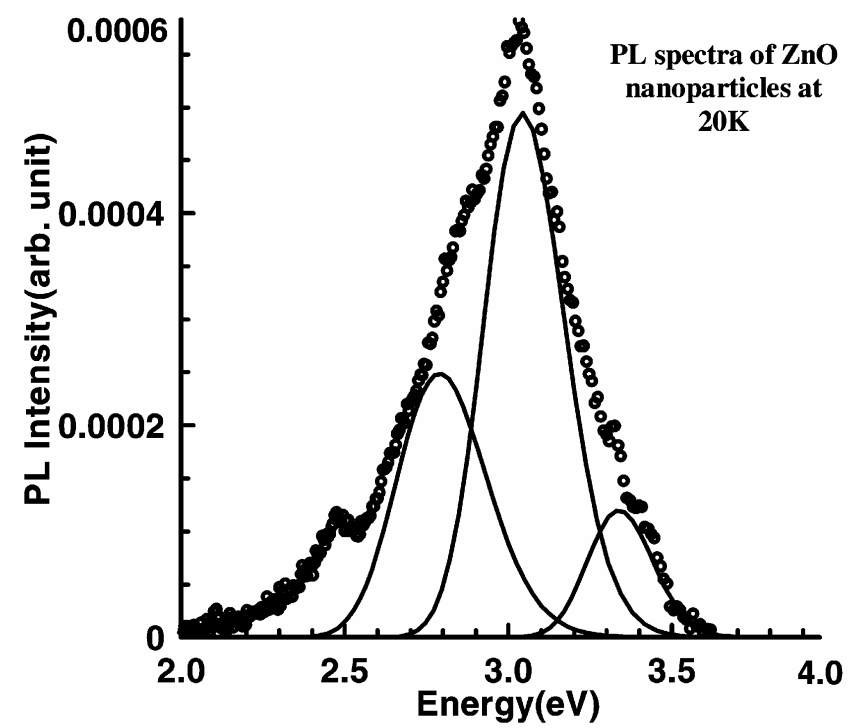

Figure 6. PL spectra of $\mathrm{ZnO}$ nanoparticles at $20 \mathrm{~K}$.

The dielectric constant $(\sim 12$ at $500 \mathrm{kHz})$ and loss $(\sim 0 \cdot 31$ at $500 \mathrm{kHz}$ ) for $\mathrm{ZrO}_{2}$ nanoparticles were highly stable with frequency at room temperature. Temperature variation studies show that the dielectric constant was stable after $100^{\circ} \mathrm{C}$, however, the dielectric loss falls to $\sim 0.03$ at $100^{\circ} \mathrm{C}$ from 0.31 at room temperature.

The variation in dielectric constant and dielectric loss with composition $(x)$ for $\mathrm{Ba}_{1-x} \mathrm{~Pb}_{x} \mathrm{ZrO}_{3}$ (table 1) (at room temperature and at $100 \mathrm{kHz}$ frequency) shows a maximum in the dielectric constant value $(\varepsilon=93)$ for $x=0.5$ composition. The dielectric properties of nanocrystalline $\mathrm{Ba}_{1-x}$ $\mathrm{Pb}_{x} \mathrm{ZrO}_{3}(0 \leq x \leq 1)$ over the entire range of $x$ values have been reported for the first time. To the best of our knowledge, this is the first report to show the presence of a maximum in the value of the dielectric constant with $\mathrm{Pb}$ content corresponding to $x=0 \cdot 5$ composition. The explanation of this trend may lie in the presence of a structural phase transition close to this composition.

We have carried out the photoluminescence studies of nanocrystalline $\mathrm{ZnO}$. Figure 6 shows three peaks in the deconvoluted photoluminescence (PL) spectra of nanocrystalline $\mathrm{ZnO}$. The peak at $3 \cdot 34 \mathrm{eV}$ corresponds to free excitonic transition, $3.04 \mathrm{eV}$ peak corresponds to free-tobound transition (FB) and $2.78 \mathrm{eV}$ peak corresponds to donor-acceptor pair (DAP). A weak peak at $2.5 \mathrm{eV}$ is due 
to the chromium present in the quartz substrate. The strong peak of the PL intensity suggests excellent sample quality.

\section{Conclusions}

Monophasic nanoparticles of $\mathrm{CeO}_{2}, \mathrm{ZrO}_{2}$ and $\mathrm{ZnO}$ were synthesized from the thermal decomposition of their respective oxalate precursors. The precursors were synthesized using the reverse micellar route. Zinc oxalate was obtained as nanorods whereas cerium oxalate particles were spherical in shape. Nanoparticles of the solid solution of $\mathrm{Ba}_{1-x} \mathrm{~Pb}_{x} \mathrm{ZrO}_{3}$ have been reported for the first time and the dielectric properties show a maximum at $x=0 \cdot 5$. The reverse micellar route was found to be a versatile route for the synthesis of a variety of oxide nanomaterials.

\section{Acknowledgements}

One of the authors (AKG) thanks the NSTI, Department of Science and Technology, Govt. of India, for financial support. (TA) and (SV) thank CSIR, Govt. of India, for fellowships. The authors also thank Dr Subhasis Ghosh, JNU, for the optical studies.

\section{References}

Ahmad T and Ganguli A K 2006 J. Am. Ceram. Soc. 891326 Ahmad T, Ramanujachary K V, Lofland S E and Ganguli A K 2004 J. Mater. Chem. 143406

Ahmad T, Kavitha G, Narayana C and Ganguli A K 2005a $J$. Mater. Res. 201415

Ahmad T, Chopra R, Ramanujachary K V, Lofland S E and Ganguli A K 2005b J. Nanosci. Nanotechnol. 51840

Ahmad T, Vaidya S, Sarkar N, Ghosh S and Ganguli A K 2006 Nanotechnology 171236

Chatterjee A, Das D, Pradhan S K and Chakravorty D 1993 J. Magn. Magn. Mater. 127214

De Merchant J and Cocivera M 1995 Chem. Mater. 71742

Erb U 1995 Nanostruct. Mater. 6533

Komarneni S, D'Arrigo M C, Leionelli C, Pellacani G C and Katsuki H 1998 J. Am. Ceram. Soc. 813041

Lin Y, Tang Z and Zhang Z 2000 J. Am. Ceram. Soc. 832869

Logothetidis S, Patsalas P, Evangelou E K, Konofaos N, Tsiaoussis I and Frangis N 2004 Mater. Sci. Eng. B109 69

Maruyama T and Shionoya J 1992 J. Mater. Sci. Lett. 11170

Pileni M P, Motte L and Petit C 1992 Chem. Mater. 4338

Roth A P and Williams D F 1981 J. Appl. Phys. 526685

Sartale S D and Lokhande C D 2000 Indian J. Eng. Mater. Sci. 7404

Vaidya S, Ahmad T, Agarwal S and Ganguli A K 2007 J. Am. Ceram. Soc. 90863 